Original Article

\title{
Effects of Indoor Horseback Riding and Virtual Reality Exercises on the Dynamic Balance Ability of Normal Healthy Adults
}

\author{
Daehee Lee, PhD, PT ${ }^{1)}$, Sangyong Lee, PhD, PT ${ }^{1)}$, Jungseo Park, PhD, PT ${ }^{1{ }^{*}}$ \\ 1) Department of Physical Therapy, Youngdong University: 12 Youngdong-eup, Youngdong-gun, \\ Chungbuk 370-701, Republic of Korea
}

\begin{abstract}
Purpose] The objective of this study was to determine the effect of indoor horseback riding and virtual reality exercises on the dynamic balance ability of normal adults. [Subjects] This study enrolled 24 normal adults and divided them into two groups: an indoor horseback riding exercise group (IHREG, $\mathrm{n}=12$ ) and a virtual reality exercise group (VREG, $\mathrm{n}=12$ ). [Methods] IHREG exercised on indoor horseback riding equipment and VREG exercised using the Nintendo Wii Fit three times a week for six weeks. The Biodex Balance System was used to analyze dynamic balance as measured by the overall stability index (OSI), anteroposterior stability index (APSI), and mediolateral stability index (MLSI). [Results] In the within-group comparison, IHREG and VERG both showed significant decreases in the dynamic balance indexes of OSI, APSI, and MLSI after the intervention, but no significant difference was found between the groups. [Conclusion] Both indoor horseback riding and virtual reality exercises were effective at improving the subjects' dynamic balance ability as measured by OSI, APSI, and MLSI, and can be used as additional exercises for patients with conditions affecting postural control.

Key words: Indoor horseback riding exercise, Virtual reality exercise, Dynamic balance
\end{abstract}

(This article was submitted May 9, 2014, and was accepted Jun. 12, 2014)

\section{INTRODUCTION}

Patients with conditions affecting postural control face difficulties performing daily living activities and therapeutic interventions because of postural disturbance and a large negative effect on muscle activity, as their sensory information is often transmitted abnormally ${ }^{1)}$.

Hippotherapy has been used to improve the postural control of such patients, but it has limited applicability due to its space requirements, cost, and the risks involved in mounting patients on live horses. To overcome these barriers, an indoor horseback riding machine has been devised and can be used as a therapeutic tool that is available any time. Indoor horseback riding exercise equipment can mimic the rhythmic motion of a horse's movement, helping riders improve their stability and flexibility, as well as developing their muscles. It can be used to improve the balance and postural control of normal and disabled individuals ${ }^{2,3)}$. Virtual reality programs using the Nintendo Wii Fit can be conveniently and inexpensively enjoyed at home. These programs often stimulate excitement and enjoyment motivating users to continue using them. Furthermore, many studies of virtual reality have been conducted and the reli-

*Corresponding author. Jungseo Park (E-mail: emotion526@ nate.com)

(C2014 The Society of Physical Therapy Science. Published by IPEC Inc. This is an open-access article distributed under the terms of the Creative Commons Attribution Non-Commercial No Derivatives (by-ncnd) License $<$ http://creativecommons.org/licenses/by-nc-nd/3.0/> ability of its therapeutic effects has been proven ${ }^{4}$. Virtual reality, the interaction between users and computers, has the advantage of providing a wider range of motions than patients might encounter in real situations.

Although many previous studies have investigated the effects of proprioceptive neuromuscular facilitation, the Bobath method, sling, and ball exercises on postural balance, comparative studies of the dynamic balance ability gains from exercise on indoor horseback riding equipment and virtual reality exercise using Nintendo Wii Fit have not yet been performed. This study aimed to determine the effects of indoor horseback riding and virtual reality exercises on dynamic balance ability.

\section{SUBJECTS AND METHODS}

The subjects of this study were 24 healthy adults in their twenties, all students of Y University in Chungbuk, who were divided into two groups: an indoor horseback riding exercise group (IHREG; $\mathrm{n}=12$, age $19.4 \pm 0.5$ years, height $163.7 \pm 6.8 \mathrm{~cm}$, weight $61.5 \pm 13.8 \mathrm{~kg}$ ) and a virtual reality exercise group (VREG; $\mathrm{n}=12$, age $19.4 \pm 0.7$ years, height $162.2 \pm 5.0 \mathrm{~cm}$, weight $53.7 \pm 5.1 \mathrm{~kg}$ ). All of the subjects received an explanation about the purpose and exercise methods of the study prior to their participation and provided their informed consent according to the ethical principles of the Declaration of Helsinki. The selected subjects had no experience of indoor horseback riding or virtual reality exercises, no medical abnormalities and were not receiving pharmacological treatments. Those who had under- 
gone muscle-strengthening training within the previous six months or who had orthopedic or neurological injuries were excluded from the study.

In this study, an electrical indoor horseback riding exercise equipment (SRIDER, Neipplus Co., Korea) was employed to simulate horseback riding exercise for the subjects. Indoor horseback riding exercise equipment-a machine that imitates the movements of a horse's backhas been widely used in Korea in recent years. The equipment used for this study is less than $1 \mathrm{~m}$ long, smaller than most existing horseback riding simulators. The intensity of the exercise can be controlled by adjusting the speed and the range of the saddle's movement. IHREG used wholebody and complex exercise programs selected from the SRIDER's built-in programs. Subjects were instructed to look forward with the shoulders in a neutral position and with a straight back while holding the handle and bending the knees at 90 degrees to keep the feet from touching the ground. The foot rest was not installed in this study. The exercise consisted of a 25-minute session three days a week for six weeks. During the same period, the VREG exercised using the Nintendo Wii Fit (Nintendo Co., Ltd., Japan). To use the Wii Fit, a subject stands on a balance plate and the virtual reality system starts a game in which the balance plate recognizes the subject's motion. When the subject redistributes his or her weight on the balance plate, the system simulates the action in the virtual reality displayed on the screen. An on-screen avatar follows the subject's movement, providing visual and auditory feedback, and the Wii Remote supplies tactile feedback by vibrating in response to the user's actions. The VREG was assigned three exercises related to balance activity that were chosen from the Wii Fit menu and are played by standing and redistributing body weight on the balance board without lifting the heels and toes. The subjects played a 25-minute sessions including Ski Slalom, Table Tile, and Balance Bubble exercises three days a week, for the first three weeks in the beginner mode, and then for three more weeks in the advanced mode.

In order to collect clinical data related to dynamic balance ability, this study used the Biodex Balance System (Biodex Medical Systems Inc., USA). Stability levels of the foot board range from Level 8, the lowest, to Level 1, the highest. To measure their posture, subjects stood on the center of the circular foot board of the Biodex Balance System which was set to Stability Level 6, with their legs about shoulder width apart and their arms resting alongside the trunk, for 40 seconds per measurement. Three measurements were taken, and subjects were allowed 10 seconds of rest on the floor between measurements. The lower the values of the overall stability index (OSI), anterioposterior stability index (APSI), and mediolateral stability index (MLSI) are, the higher a subject's balance ability is.

The paired t-test was employed to determine the significance of differences in dynamic balance ability between before and after the intervention within each group, while the independent sample t-test was conducted to compare dynamic balance ability between the two groups. The present study used SPSS 12.0 Windows for statistical processing, and a significance level of 0.05 .
Table 1. Comparison of the dynamic balance index results of both groups

(Unit: point)

\begin{tabular}{llll}
\hline Index & Group & Before & After \\
\hline OSI & IHREG** & $5.2 \pm 2.6$ & $3.1 \pm 1.4$ \\
& VREG** & $4.2 \pm 1.8$ & $2.7 \pm 0.6$ \\
\multirow{2}{*}{ APSI } & IHREG** $^{*}$ & $3.4 \pm 1.5$ & $2.0 \pm 0.9$ \\
& VREG** & $2.6 \pm 1.2$ & $1.7 \pm 0.5$ \\
\multirow{2}{*}{ MLSI } & IHREG** & $3.2 \pm 1.8$ & $1.9 \pm 1.0$ \\
& VREG** & $2.8 \pm 1.2$ & $1.6 \pm 0.4$ \\
\hline
\end{tabular}

OSI: overall stability index, APSI: anterioposterior stability index, MLSI: mediolateral stability index, VREG: virtual reality exercise group, IHREG: indoor horseback riding exercise group, ${ }^{* *}$ : paired t-test, $\mathrm{p}<0.01$

\section{RESULTS}

After the intervention, both IHREG and VERG showed significant decreases in average OSI, APSI, and MLSI ( $p<$ $0.05)$, but no significant difference was found between the two groups $(\mathrm{p}>0.05)$ (Table 1).

\section{DISCUSSION}

This study aimed to determine the effect of indoor horseback riding exercise using indoor horseback riding equipment and virtual reality exercise using the Nintendo Wii Fit on the dynamic balance ability of normal adults.

Cho et al. ${ }^{5)}$ reported that 30 subjects improved their postural balance ability and proprioception by using a horseback riding simulator. Kuczyński and Słonka ${ }^{6}$ presented evidence that after 25 subjects with cerebral palsy had used horseback riding simulators for 12 weeks, their right and left balance ability improved significantly. In addition, Lee et al. ${ }^{7)}$ reported that a horseback riding simulator used for hippotherapy improved both the static and the dynamic balance of children with cerebral palsy. Beinotti el al. ${ }^{8)}$ reported that 20 stroke patients who received hippotherapy found their gait and balance ability improved. Park et al. ${ }^{9)}$ also reported that use of a horseback riding simulator improved the eyes-closed balance and dynamic balance ability of patients with chronic stroke.

Dunning et al. ${ }^{10)}$ reported that after patients with stroke performed exercises using virtual reality systems for eight weeks, they showed improvements in gait speed, ankle movement, and plantar flexion while pushing the ankle, as well as increases in ankle muscle strength and gait speed. Walker et al. ${ }^{11)}$ reported that weight-supported treadmill training performed by patients with chronic stroke in a virtual environment was more effective at improving their balance than treadmill training in a normal environment. Yavuzer et al. ${ }^{12)}$ studied 20 patients with stroke and found that a group that performed virtual reality exercises for four weeks showed a significant increase in upper extremity functions, such as dressing, in terms of functional independence measures, compared to a placebo group. Park et al. ${ }^{13)}$ reported that a virtual reality exercise significantly increased the muscle activities of the tibialis anterior and medial gastrocnemius muscles. Merians et al. ${ }^{14)}$ also studied 
stroke patients and reported that virtual reality programs using robots, motion detection, sensor-attached gloves, and computers were effective for the recovery of upper extremity functions. The same study explained that the addition of virtual reality to traditional exercise treatments can be more beneficial, because exercise intervention using virtual reality can provide appropriately modified visual feedback to further activate brain tissues.

In the present study, the within-group comparison after the intervention revealed that both IHREG and VERG showed significant decreases in dynamic balance indexes of OSI, APSI, and MLSI. We speculate that the subjects in IHREG improved the strength of the main muscles of the lower extremities and trunk, as well as proprioception, thereby increasing their dynamic balance ability. Subjects in VERG changed their center of pressure using forward, backward, right and left movements during virtual reality balance training which would have improved the stability of their ankle joints through the frequent use of the muscles in the ankles, thereby improving their dynamic balance ability. Despite the differing gains experienced by the two groups, no significant difference in the dynamic balance indexes was found in the post-intervention comparison of the groups. Both indoor horseback riding and virtual reality exercises can be performed indoors, solving the cost and space problems associated with traditional hippotherapy and providing patients with conditions to postural control with additional exercises for improving their balance ability.

One limitation of this study was the small number of subjects which precludes the generalization of the results. Furthermore, no follow-up was done to evaluate the residual effects following completion of the experimental indoor horseback riding and virtual reality exercise interventions. This study should be repeated with a greater number of subjects and an increased exercise duration to determine which exercises would be most appropriate for patients with postural control problems.

\section{REFERENCES}

1) Hlavacka F, Horak FB: Somatosensory influence on postural response to galvanic vestibular stimulation. Physiol Res, 2006, 55: S121-S127. [Medline]

2) Sterba JA: Does horseback riding therapy or therapist-directed hippotherapy rehabilitate children with cerebral palsy? Dev Med Child Neurol, 2007, 49: 68-73. [Medline] [CrossRef]

3) Janura M, Peham C, Dvorakova T, et al.: An assessment of the pressure distribution exerted by a rider on the back of a horse during hippotherapy. Hum Mov Sci, 2009, 28: 387-393. [Medline] [CrossRef]

4) Clark RA, Bryant AL, Pua Y, et al.: Validity and reliability of the Nintendo Wii Balance Board for assessment of standing balance. Gait Posture, 2010, 31: 307-310. [Medline] [CrossRef]

5) Cho WS, Kim YN, Park JS, et al.: The effects of ability to balance posture and proprioception by horse riding simulator and galvanic vestibular stimulation. Phys Ther Kor, 2012, 19: 39-47. [CrossRef]

6) Kuczyński M, Słonka K: Influence of artificial saddle riding on postura stability in children with cerebral palsy. Gait Posture, 1999, 10: 154-160. [Medline] [CrossRef]

7) Lee CW, Kim SG, Na SS: The effects of hippotherapy and a horse riding simulator on the balance of children with cerebral palsy. J Phys Ther Sci, 2014, 26: 423-425. [Medline] [CrossRef]

8) Beinotti F, Correia N, Christofoletti G, et al.: Use of hippotherapy in gait training for hemiparetic post-stroke. Arq Neuropsiquiatr, 2010, 68: 908913. [Medline] [CrossRef]

9) Park J, Lee S, Lee J, et al.: The effects of horseback riding simulator exercise on postural balance of chronic stroke patients. J Phys Ther Sci, 2013 , 25: 1169-1172. [Medline] [CrossRef]

10) Dunning K, Levine P, Schmitt L, et al.: An ankle to computer virtual reality system for improving gait and function in a person 9 months poststroke. Top Stroke Rehabil, 2008, 15: 602-610. [Medline] [CrossRef]

11) Walker ML, Ringleb SI, Maihafer GC, et al.: Virtual reality-enhanced partial body weight-supported treadmill training poststroke: feasibility and effectiveness in 6 subjects. Arch Phys Med Rehabil, 2010, 91: 115-122. [Medline] [CrossRef]

12) Yavuzer G, Senel A, Atay MB, et al.: "Playstation eyetoy games" improve upper extremity-related motor functioning in subacute stroke: a randomized controlled clinical trial. Eur J Phys Rehabil Med, 2008, 44: 237-244. [Medline]

13) Park J, Lee D, Lee S: Effect of virtual reality exercise using the nintendo wii fit on muscle activities of the trunk and lower extremities of normal adults. J Phys Ther Sci, 2014, 26: 271-273. [Medline] [CrossRef]

14) Merians AS, Tunik E, Adamovich SV: Virtual reality to maximize function for hand and arm rehabilitation: exploration of neural mechanisms. Stud Health Technol Inform, 2009, 145: 109-125. [Medline] 